\title{
Simulation and Optimization of Air-Cooled PEMFC Stack for Lightweight Hybrid Vehicle Application
}

\author{
Jingming Liang and Zefeng Wu \\ Department of Automotive Engineering, Guangdong Polytechnic Institute, Guangzhou 510091, China \\ Correspondence should be addressed to Jingming Liang; liangjingming_2013@163.com
}

Received 4 April 2015; Revised 27 June 2015; Accepted 5 July 2015

Academic Editor: Mohsen Torabi

Copyright (C) 2015 J. Liang and Z. Wu. This is an open access article distributed under the Creative Commons Attribution License, which permits unrestricted use, distribution, and reproduction in any medium, provided the original work is properly cited.

\begin{abstract}
A model of $2 \mathrm{~kW}$ air-cooled proton exchange membrane fuel cell (PEMFC) stack has been built based upon the application of lightweight hybrid vehicle after analyzing the characteristics of heat transfer of the air-cooled stack. Different dissipating models of the air-cooled stack have been simulated and an optimal simulation model for air-cooled stack called convection heat transfer (CHT) model has been figured out by applying the computational fluid dynamics (CFD) software, based on which, the structure of the air-cooled stack has been optimized by adding irregular cooling fins at the end of the stack. According to the simulation result, the temperature of the stack has been equally distributed, reducing the cooling density and saving energy. Finally, the $2 \mathrm{~kW}$ hydrogen-air air-cooled PEMFC stack is manufactured and tested by comparing the simulation data which is to find out its operating regulations in order to further optimize its structure.
\end{abstract}

\section{Introduction}

Air-cooled PEMFC is applied in some vehicles whose power requirements are not demanding because of its compact structure, low cost, and convenience to use. Most of its stack power is between $500 \mathrm{~W}$ and $5 \mathrm{~kW}$; supposing power higher than $5 \mathrm{~kW}$, the stack requires water cooling to dissipate heat. Due to its power limit, it is mostly applied in compact vehicles, such as golf carts, tour buses, and factory forklift trucks.

Currently, there are two kinds of air-cooled stack research orientations: one is to design various radiators, say, Boyd and Hooman [1], who study medal bubble micropore heat exchanger, whose simulation result shows that the temperature is uniform in the stack whose effect is similar to that of the water-cooled with small volume; Wan Mohamed et al. [2] designed some extending ribs in its superficial area to lose heat, whose heat dissipating efficiency can be improved by $30 \%$. The other is the simulation and testing analysis of the flow field. Akbari et al. [3], diffusion layer and different Renaults are applied to evaluate air-cooled convection heat dissipating efficiency, whose results show that the former is less influential, yet, the range of temperature changes dramatically as the Renaults reduce. Adzakpa et al. built air-cooled model [4], whose simulation results show that different voltage distribution causes the decline of the whole stack power.

Based on the previous studies, this paper aims to further optimize the heat dissipating structure of the air-cooled stack and to make the stack temperature distribution more reasonable, including the following: (1) the stack temperature distribution is simulated and analyzed in different surface heat dissipation models; (2) the structure of heat dissipating outlet in air-cooled stack is optimized; (3) $2 \mathrm{~kW}$ air-cooled stack is designed and manufactured, which is applied to test and analyze in lightweight vehicle.

\section{Air-Cooled Stack Heat Transfer and Heat Dissipation Model}

2.1. The Generation of Stack Heat. More than half of the consuming energy produced in the PEMFC electrochemistry reaction dissipates in the form of heat energy [5]; in this case, in order to keep the stack operate within reasonable temperature, it is required to have the nature of heat dissipation. 
These heat energies mainly embrace chemistry respondent heat, ohm heat, phase change heat, and entropy increasing heat, of which the first one is irreversible, whereas the last one is reversible; in addition, some sensible heat forms the temperature difference between the inlet gas and the outlet one. Therefore, the necessary dissipating heat of every single cell is composed of reversible heat, irreversible heat, and sensible heat, which can be expressed as below $[4,6]$ :

$$
Q_{h}=Q_{\text {rev }}+Q_{\text {irrev }}+Q_{\text {sens }} \text {, }
$$

where $Q_{\text {rev }}$ is reversible heat, J; $Q_{\text {irrev }}$ is irreversible heat, J; and $Q_{\text {sens }}$ is sensible heat, J:

$$
\begin{aligned}
Q_{\text {rev }} & =\left(-T_{\text {cell }} \Delta S_{T}\right) \frac{I_{\text {cell }}}{n F}, \\
Q_{\text {irrev }} & =\left(-\frac{\Delta G_{T}}{n F}-V_{\text {cell }}\right) I_{\text {cell }}, \\
\Delta G_{T} & =\Delta H_{T}-T_{\text {cell }} \Delta S_{T},
\end{aligned}
$$

where $I_{\text {cell }}$ is stack current, A; $T_{\text {cell }}$ is stack average temperature, $\mathrm{K} ; V_{\text {cell }}$ is stack voltage, $\mathrm{V} ; G_{T}$ is Gibbs free energy, $\mathrm{kJ} / \mathrm{mol} ; F$ is Faraday constant, $\mathrm{C} / \mathrm{mol}$; and $\Delta S_{T}$ and $\Delta H_{T}$ are total entropy and total enthalpy of the supplying gas:

$$
Q_{\text {sens }}=Q_{\text {sens }}^{\text {in }}-Q_{\text {sens }}^{\text {out }} \text {, }
$$

where $\mathrm{Q}_{\text {sens }}{ }^{\text {in }}$ and $\mathrm{Q}_{\text {sens }}{ }^{\text {out }}$ are the inlet and outlet sensible heat of total reactant gas, J:

$$
Q_{h}=\left(-\frac{\Delta H_{T}}{n F}-V_{\text {cell }}\right) I_{\text {cell }}+Q_{\text {sens }} .
$$

Accordingly, the heat produced in a single cell is the total power of the electrochemistry; respondent subtracts the power that the cell gives out and adds the total sensible heat of the inlet and outlet gas, whose expression is shown in (4). The heat generation of stack is the total heat generated from every single cell:

$$
Q_{\text {stack }}=n Q_{h} .
$$

2.2. The Heat Dissipation of Stack. The air-cooled stack requires to discontinuously dissipate heat so as to maintain its steady operation. The main approaches of heat dissipation include forcing convection heat dissipation whose heat is dissipated by the air of the cooling plate and natural convection and radiation on the stack surface; yet, radiation merely dissipates a little heat due to the low operation temperature of the stack; in addition, the inlet and outlet of the respondent gas also dissipate some heat; heat conduction loses less heat, which can be neglected; therefore, the stack heat dissipation can be expressed as [7]

$$
Q_{\text {stack }}=\sum_{i}\left(\dot{m}_{\text {out }}^{i} C_{p}^{i} T_{\text {out }}-\dot{m}_{\text {in }}^{i} C_{p}^{i} T_{\text {in }}\right)+Q_{\text {conv }}+Q_{\text {rad }}
$$

where $i$ is some kind of reactant gas; $\dot{m}_{\text {out }}^{i}$ and $\dot{m}_{\text {in }}^{i}$ are the quality flow of the outlet and inlet reactant, $\mathrm{kg} / \mathrm{s}$; and $T$ is the temperature, $\mathrm{K}$.
Single cell and cooling border to conduct convection heat exchange can be expressed as

$$
Q_{\text {nat,for }}^{\text {conv }}=-\lambda \cdot \bar{\nabla} T
$$

where forcing convection can be expressed as

$$
Q_{\text {for }}^{\text {conv }}=\zeta h_{\text {for }}\left(T_{\text {cell }}-T_{\text {in }}\right) \text {, }
$$

where $\zeta$ is blades' modulus and $h_{\text {for }}$ is the forcing convection modulus, $\mathrm{W} /\left(\mathrm{m}^{2} \cdot \mathrm{K}\right)$, where natural convection can be expressed as

$$
Q_{\text {nat }}^{\text {conv }}=h_{\text {nat }}\left(T_{\text {cell }}-T_{\mathrm{amb}}\right) \text {, }
$$

where $h_{\text {nat }}$ is the natural convection modulus, $\mathrm{W} /\left(\mathrm{m}^{2} \cdot \mathrm{K}\right)$ and $T_{\mathrm{amb}}$ is the surrounding atmosphere temperature, $\mathrm{K}$.

Radiation heat can be expressed as

$$
Q_{\mathrm{rad}}=\delta \cdot \sigma_{b} \cdot A_{\mathrm{rad}} \cdot\left(T_{\mathrm{cell}}^{4}-T_{\mathrm{amb}}^{4}\right),
$$

where $\delta$ is stack blackness; $\sigma_{b}$ is Stefan-Boltzmann constant; and $A_{\text {rad }}$ is the stack radiation area, $\mathrm{m}^{2}$.

The convection exchange heat modulus $h_{\text {for }}$ is obtained according to the equation

$$
\mathrm{Nu}=\frac{D h_{\text {for }}}{\lambda}=1.86\left(\operatorname{RePr} \frac{D}{L}\right)^{1 / 3}\left(\frac{\mu}{\mu_{p}}\right)^{0.14},
$$

where $\lambda$ is the air heat conduction modulus, $\mathrm{W} / \mathrm{m}^{2} \cdot \mathrm{K} ; D$ is the hydraulic diameter, $\mathrm{m}$; $\operatorname{Pr}$ is the Prandtl number; $L$ is the length of the water hose, $\mathrm{m}$; and Re is the Reynolds number:

$$
\begin{aligned}
& \mathrm{Nu}=0.664 \operatorname{Pr}^{1 / 3} \operatorname{Re}^{1 / 2}, \\
& \mathrm{Re}=\frac{\mathrm{UL}}{\mu}
\end{aligned}
$$

2.3. The Simulation Model of Different Heat Dissipation for Air-Cooled Stack. When CFD software is applied to simulate PEMFC, the surface heat dissipating models can be categorized to be five [8]: specified heat flux, specified temperature (ST), CHT, external radiation, combined external radiation, and external convective heat transfer. The latter three heat dissipating models have been analyzed from (8) to (10); the first model is usually applied in the insulation layer, whose heat flow is set to be zero that can be skipped. The ST dissipating model can be divided into fluid surface and solid surface, which can be expressed as follows.

For fluid surface, consider

$$
Q=h_{f}\left(T_{w}-T_{f}\right)+Q_{\mathrm{rad}}
$$

where $h_{f}$ is fluid-side local heat transfer coefficient and $T_{w}$ and $T_{f}$ are wall surface temperature and local fluid temperature, respectively, $\mathrm{K}$.

For solid surface, consider

$$
Q=\frac{\lambda_{s}}{\Delta n}\left(T_{w}-T_{s}\right)+Q_{\mathrm{rad}}
$$




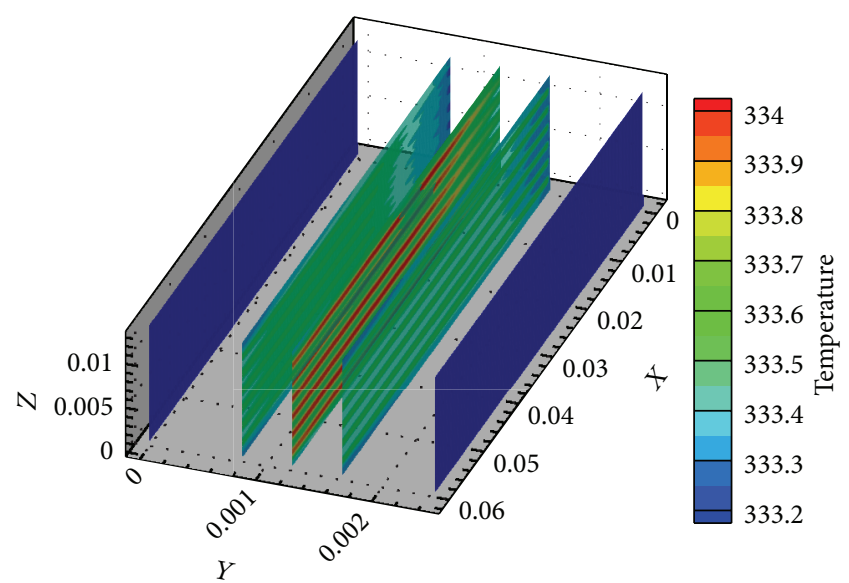

(a) ST model

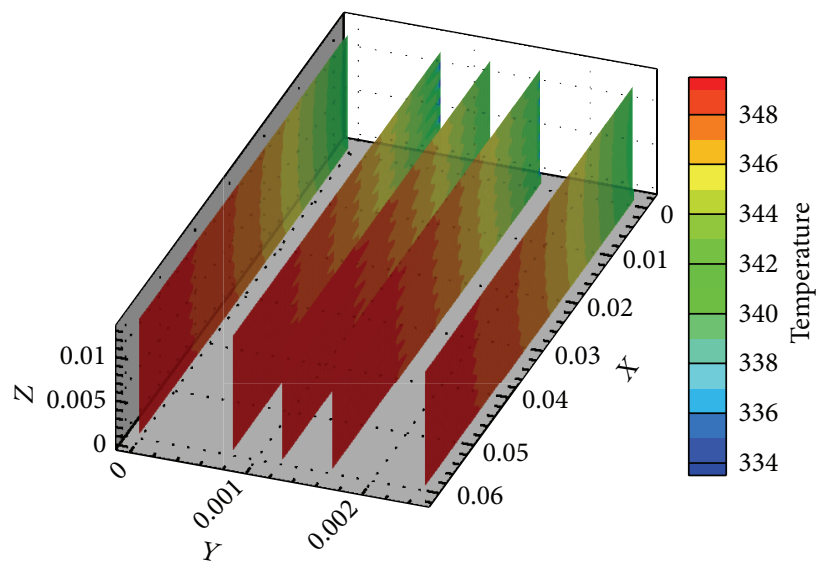

(b) CHT model

FIGURE 1: The model of surface heat transfer.

where $\lambda_{s}$ is thermal conductivity of the solid, $\mathrm{W} /(\mathrm{m} \cdot \mathrm{K}) ; T_{s}$ is local solid temperature, $\mathrm{K}$; and $\Delta n$ is distance between wall surface and the solid cell center, $\mathrm{m}$.

The ST heat dissipating model is usually used in the simulation of the water-cooled PEMFC stack; references [8-10] use this model to analyze. In addition, different flow fields are analyzed, such as parallel, interdigital, and serpentine ones [11-14]. ST model is also applied to compare their advantages and disadvantages, so as to find out the distributions of the temperature and the current density. However, as for the aircooled PEMFC stack, ST model cannot work properly, as aircooled intensity is lower than that of the water-cooled one. Generally, straight flow path is employed to dissipate heat, which is not uniform. Figure 1 is the surface cooling model: (a) is ST model and (b) is CHT model; seeing from the outer surface of the two models, the former can make the face temperature uniform, whereas temperature grads emerge in the latter; in this case, CHT model is similar to that of the air-cooled stack.

\section{The Simulation Model of Air-Cooled Stack and Optimization of Heat Dissipation Structure}

3.1. The Simulation Model of Air-Cooled Stack. The dimension applied in the simulation model of $2 \mathrm{~kW}$ air-cooled PEMFC stack is $60 \mathrm{~mm} * 100 \mathrm{~mm} * 345.68 \mathrm{~mm}(L * W * H(X * Y * Z))$. Because of the limitation of the hardware equipments, the whole stack cannot be simulated. In this case, the simulation model makes correspondent assumption: the heat dissipation conditions of every single fuel cell are uniform, whose height orientation of the stack is $Y$; the temperature distribution of every part of every single cell is also uniform. The reactant is ideal gas, whose gas flow in the flow field is the laminar flow. According to the assumption, the section of single cell is selected to conduct simulation, whose size $L * W * H$ $(X * Y * Z)$ is set to be $60 \mathrm{~mm} * 13 \mathrm{~mm} * 2.46 \mathrm{~mm}$; see Figure 2 .

The grid division is of vital importance; FLUENT is employed to conduct simulation, supposing the grids are too

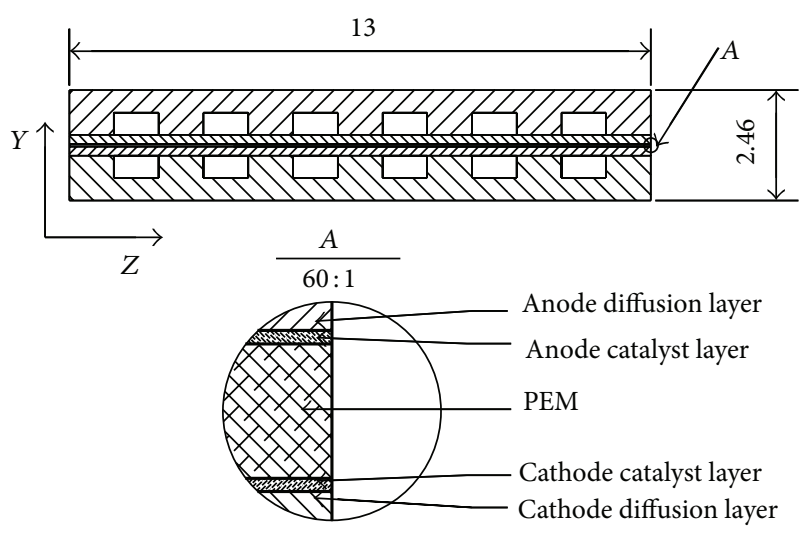

Figure 2: Model of single fuel cell.

close, this will result in slow computation; if the grids are too sparse, the calculation result will not be precise and will be inferior; therefore, several tests of mesh were done in advance, and, finally, the meshing scheme of the simulation model is determined. In the length direction, the grid is divided to be 600 sections; in width, the grid is divided to be 130 sections; in the height, current collector, flow channel, diffusion layer, catalyst layer, and membrane are divided to be sections of $10,5,5,5$, and 5 . By simulation, the model can achieve the expected results.

3.2. The Optimization of Heat Dissipation Structure in AirCooled Stack. According to Figure 1(b), the temperature is the highest in air-cooled stack terminal; in order to protect some parts of the stack from excessive heating that causes damage to proton exchange membrane (PEM), the stack terminal needs changing so as to increase the heat dissipation intensity of the stack outlet.

Figure 3 shows heat dissipation model of $2 \mathrm{~kW}$ air-cooled stack, in which 36 cooling plates with thickness of $2 \mathrm{~mm}$ are inserted in 110 single fuel cells and one cooling plate is added to every three fuel cells. Channels of the cooling plate and the 

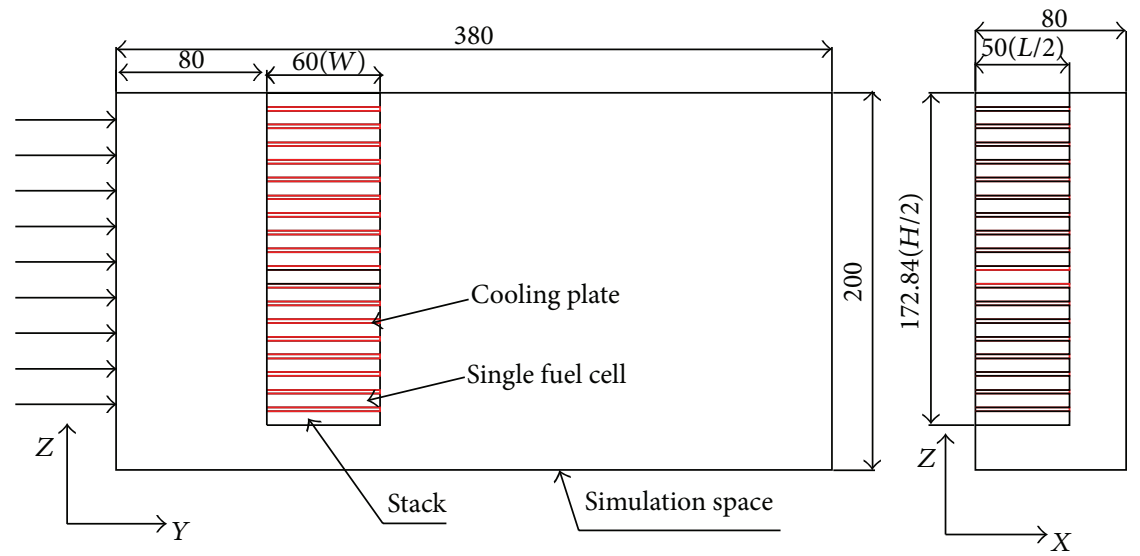

(a) NCAF
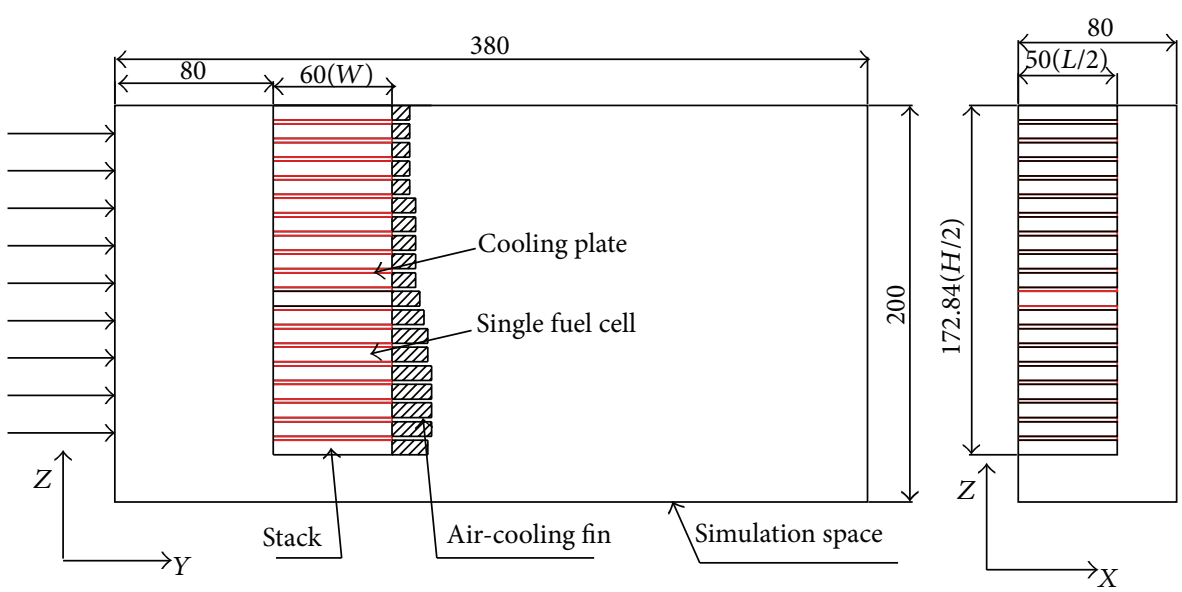

(b) CAF

Figure 3: The simulation diagram of heat transfer of air-cooled stack.

reactant both undertake the cooling task. Irregular aluminum fins are designed in the stack cooling end to reinforce its heat dissipation of the stack outlet; see Figure 3(b).

In order to facilitate CFD computation, the heat quantity of every cell is assumed to be equal; in this case, symmetry calculation is conducted between the height and the length of the stack, which reduces computation storage requirements and saves calculating time. A quarter of the stack is put into a simulation space within a dimension of $380 \mathrm{~mm} * 200 \mathrm{~mm} *$ $80 \mathrm{~mm}$, as shown in Figure 3. In the $X$ direction, $X=0$ is symmetry plane, and $X=80$ is convection dissipating surface; in the $Y$ direction, $Y=0$ is cooling air inlet and $Y=$ 380 is hot air outlet of the stack end; in the $Z$ direction, $Z=0$ is the heat insulation wall and $Z=200$ is symmetry plane. Figure 3(a) is no cooling aluminum fin (NCAF); Figure 3(b) is irregular cooling aluminum fin (CAF). The difference of which is that the cell dissipating ability differs in different parts of stack. Therefore, irregular cooling fin is set up at the end of the stack outlet in order to make the stack temperature allocation more even.

By calculating with the above equations, the necessary heat dissipation of the whole stack is approximately $2145 \mathrm{~W}$ with a voltage of $0.6 \mathrm{~V}$ single cell, whereas it needs a heat dissipation of $2805 \mathrm{~W}$ with a voltage of $0.4 \mathrm{~V}$ single cell. In order to prevent membrane damage of the stack caused by large current density, heat dissipation is calculated with a voltage of $0.4 \mathrm{~V}$. The bulk of the whole stack is $0.00207036 \mathrm{~m}^{3}$; therefore, the stack energy source value is $1354837 \mathrm{~W} / \mathrm{m}^{3}$, which is used to simulate calculation.

\section{The Development of Air-Cooled Stack}

Besides stack, fuel cell system includes hydrogen supply, oxygen supply, and water and heat management, which are not suitable for lightweight vehicle due to their complex structure. The fuel cell system development in this paper is simplified based upon the above, whose cooling system uses air-cooled; namely, the fan is applied to supply cathode with required oxygen and cools the stack that control its temperature within a reasonable range. Therefore, a selfhumidifying hydrogen-air PEMFC stack is designed based on the demand of simulation and real vehicle, whose parameters of the stack performance are shown in Table 1. 


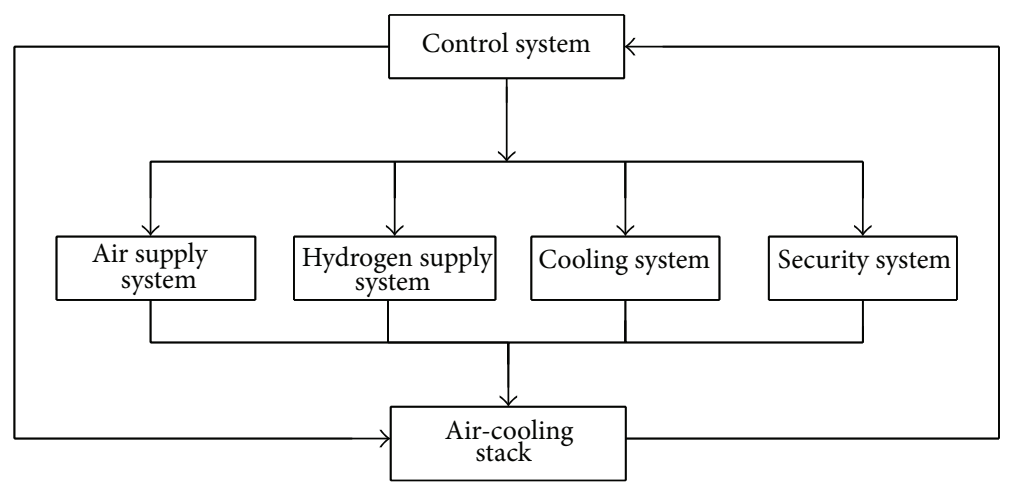

FIgURE 4: The flow chart of stack control system.

TABLE 1: Parameters of the stack performance.

\begin{tabular}{lc}
\hline Name & Parameters \\
\hline Total fuel cell number & 110 pieces \\
Weight & $12 \mathrm{~kg}$ \\
Rated efficiency (room temperature is & $2 \mathrm{~kW}$ \\
$293.15 \mathrm{~K}$; relative humidity is $40-70 \%)$ & $66 \mathrm{~V}$ \\
Rating voltage & $30 \mathrm{~A}$ \\
Rating current & $112 \pm 4 \mathrm{~V}$ \\
Open voltage & $0.5-0.6 \mathrm{bars}$ \\
Hydrogen pressure & Air (normal pressure) \\
Oxidant, coolant & $273.15 \sim 313.15 \mathrm{~K}$ \\
Environmental temperature & $20-90 \%$ \\
Environmental humidity & $298.15 \sim 333.15 \mathrm{~K}$ \\
Stack temperature & Self-humidifying \\
Humidifying method &
\end{tabular}

In the designing and manufacturing procedure, refer to the simulation requirements without adding cooling fin at the end of the cooled stack, whose operating temperature is not superheat. If superheat, it will result in fracture of the PEM that leads to accidents. The fuel cell system structure mainly contains five systems: air supply and cooling, hydrogen supply, security, stack, and control, which are shown in Figure 4.

Figure 5 shows the operating system of the air-cooled stack. Cathode applies air with self-humidifying and anode applies pure hydrogen without humidifying. In order to guarantee the normal operation of the stack, the heat and gas management is mainly considered when they are designed. In addition, security control system is designed so as to prevent the hydrogen leakage that results in accidents. Figure 5(a) shows the hydrogen supply and security system, whose stack controller controls solenoid valve and ventilating fan by collecting the signals of inlet temperature and pressure, mass flow, and hydrogen security alert. When noticing problems that emerge in the hydrogen supply system, such as hydrogen leakage, extreme pressure, or temperature, the controller immediately sends signals to the solenoid valve, which is to be blocked. If hydrogen leaks, ventilating fan is required to increase speed to prevent the hydrogen from gathering to avoid danger. When the operation finishes, switch off the hydrogen screwed valve. Switch on the nitrogen screwed valve, making the hydrogen channel filled with nitrogen; in the end, block the inlet and outlet of the hydrogen channel, preventing the air from entering and destroying the whole stack; finally, turn off the nitrogen screwed valve. Figure 5(b) shows oxygen supply system and cooling system. A suite of integrated control system was designed owing to simplification, whose requirements are to, respectively, calculate the volumes of reaction and cooling wind. The controller collects the temperature and pressure of the air inlet, analyzing the real operation circumstances of the stack; on discovering the excessive pressure of the air supply and the stack overheat, the signals are sent to the air supply solenoid valve, shutting the air supply, meanwhile, notifying the cooling fan, reinforcing the air cooling in order to guarantee the stack security. When the operation finishes, block the air inlet and outlet to prevent other things from entering and destroying the stack.

\section{Results and Discussions}

\subsection{The Performance Parameters' Effect on Stack}

(1) Relative Humidity (RH) Effect on the Air-Cooled PEMFC. Three flow fields are applied in the simulation, including the parallel flow, serpentine flow, and interdigital flow. The RH influence on the stack performance is analyzed under the conditions with single cell voltage of $0.6 \mathrm{~V}$, parallel flow field, and ST model.

Figure 6 shows the current density of the stack with different RH, whose anode is not humidified. The RH of cathode range is from zero to $100 \%$, which is simulated gradually; in order to reduce the simulation calculation, $\mathrm{RH}$ of $30 \%$, $50 \%, 80 \%$, and $100 \%$ is selected to be analyzed. Figure 6 shows the important effect on the stack performance with humidification in the cathode. Without humidity, the current density of the stack is $0.3186 \mathrm{~A} / \mathrm{cm}^{2}$, when humidifying the cathode with a $\mathrm{RH}$ of $30 \%$, the current density of the stack is $0.6042 \mathrm{~A} / \mathrm{cm}^{2}$, and when the $\mathrm{RH}$ is of $80 \%$, the current density of the stack reaches the maximum $0.6042 \mathrm{~A} / \mathrm{cm}^{2}$. When the $\mathrm{RH}$ reaches $100 \%$, the current density drops slightly. In 


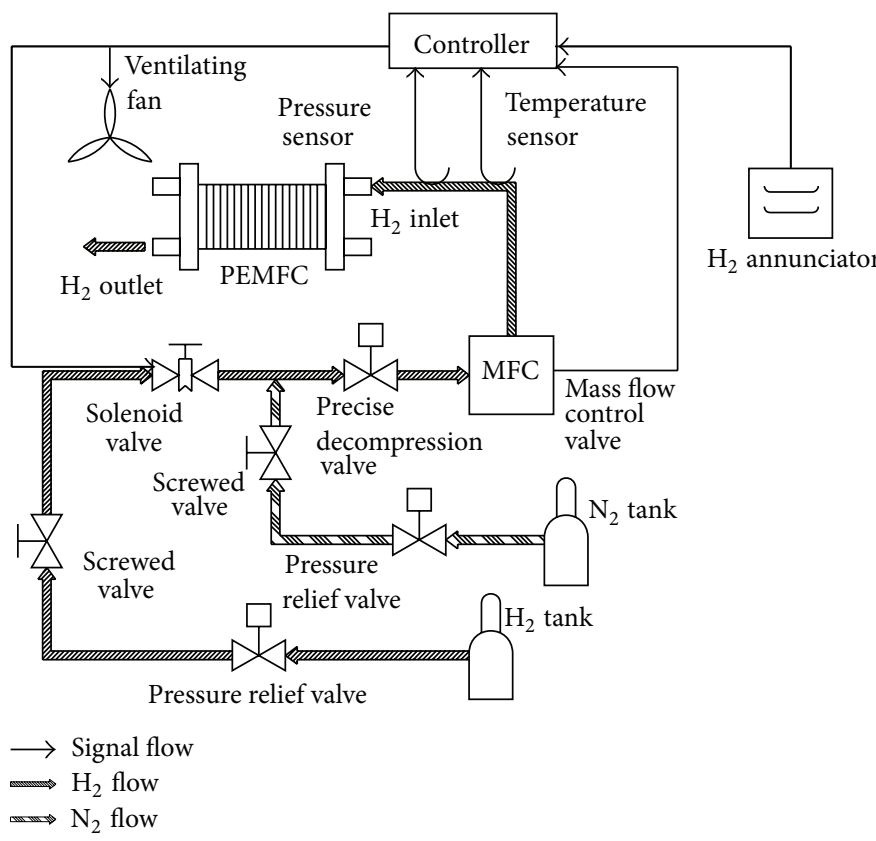

(a) Hydrogen supply system and security system

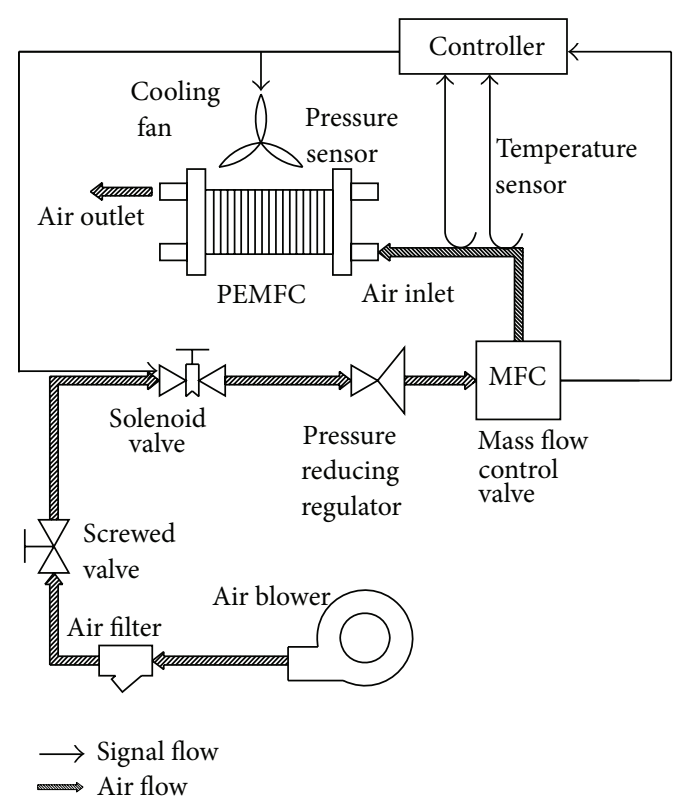

(b) Oxygen supply system and cooling system

FIGURE 5: The operating system of stack.

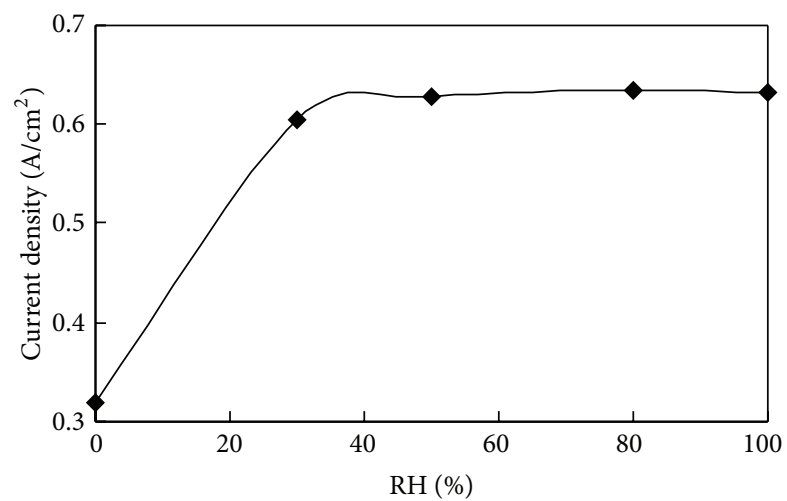

FIgURE 6: Current density versus RH.

this case, the following simulation is analyzed based on the cathode with a $\mathrm{RH}$ of $80 \%$.

(2) The Characteristic Curves Analysis of the Air-Cooled Stack. Based on the above analysis, simulation is conducted under the conditions of $\mathrm{RH}$ of $80 \%$ in the cathode, parallel flow field, and CHT model; the simulated characteristic curve, whose result is shown in Figure 7, shows that the $2 \mathrm{~kW}$ stack model and test data are similar; therefore, the model is verified. Although there are some small differences mainly because of the degradation of the air-cooled stack whose open circuit voltage is $103.8 \mathrm{~V}$ which cannot reach $110 \mathrm{~V}$, in this case, one of the flaws of the air-cooled stack is its easy degradation to lead power decreasing under low current density. Under high current density, the operation temperature is low and easy to

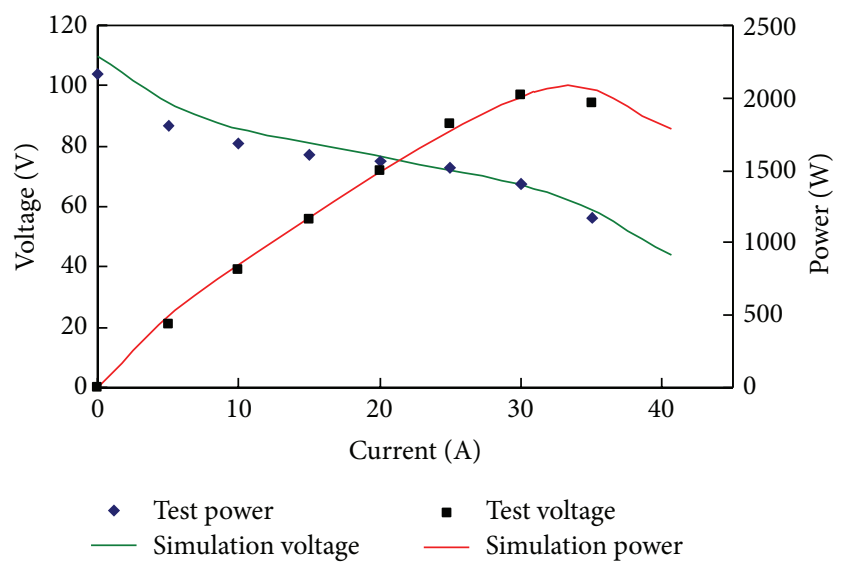

FIgURE 7: The curve volt-ampere and power of stack.

produce water flooding [15-18], which results in the power decreasing.

(3) The Influence of Heat Dissipating Model on Stack Performance. Figure 8 shows the reaction of temperature and water content in the PEM center, with different heat dissipating models, when the single fuel cell voltage is $0.6 \mathrm{~V}$.

Seeing from Figure 8(a), the temperature in the CHT of PEM is increasing along channel, whose temperature changes from $342 \mathrm{~K}$ in the inlet to $348 \mathrm{~K}$ in the outlet; whereas $\mathrm{CHT}$ model is not ideal, it cannot make the stack operate at the $333.15 \mathrm{~K}$; yet, the ST model can better control the stack temperature, ensuring the normal operation of the stack. 


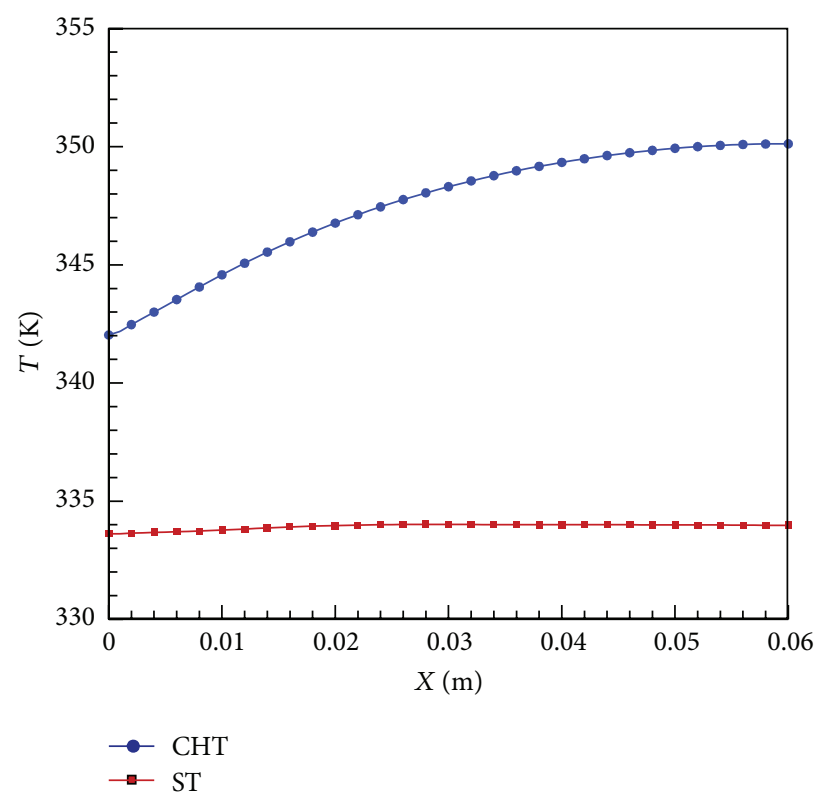

(a) Temperature curve

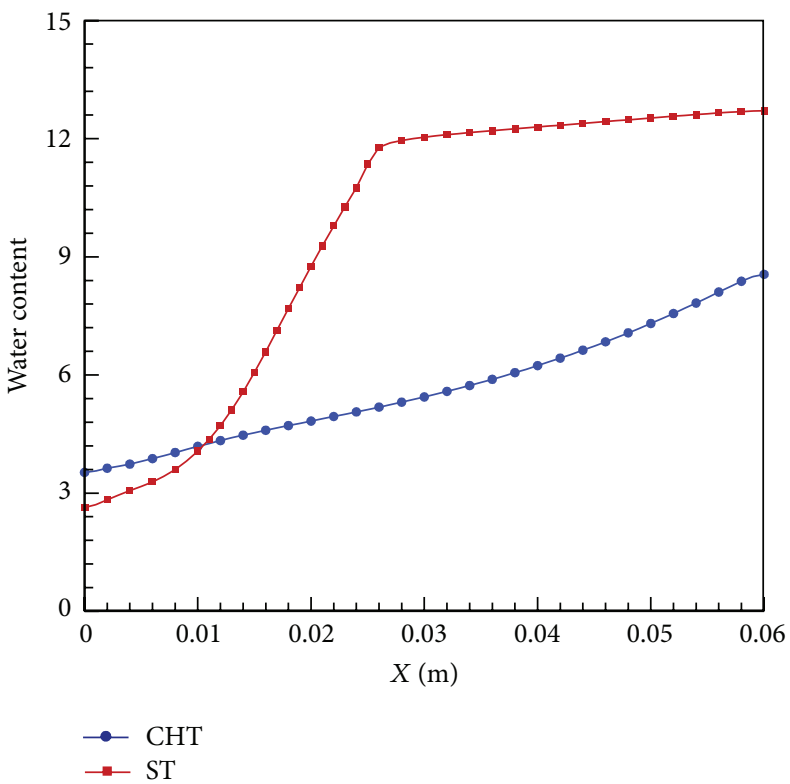

(b) Water content curve

FIgURE 8: $Y=1.23 \mathrm{~mm}$, the characteristic curves of the temperature and water content of membrane along channel.

Figure 8(b) shows the water content situation of PEM along the channel, as the temperature of CHT mode is high; therefore, its water content is low, whereas the stack temperature of ST mode is well controlled with high water content. Yet, When $X$ reaches $30 \mathrm{~mm}$, the water content can increase a little and reach saturation, which manifests that water flooding produced in ST mode. Furthermore, two dissipating modes produce different current densities; the current density of ST mode is $0.6342 \mathrm{~A} / \mathrm{cm}^{2}$, but the current density of CHT mode is $0.5198 \mathrm{~A} / \mathrm{cm}^{2}$.

Therefore, ST mode is closer to perfect heat dissipating mode and its stack can equally dissipate heat, the maximum reactant temperature is in the membrane accessory, and the current density produced is high; yet, when operating with low temperature, it tends to produce water flooding. The CHT mode is closer to air-cooled stack, whose outlet temperature is too high to dissipate heat, which needs to increase aircooling.

(4) Different Flow Fields Affect PEMFC under CHT Model. The flow field of air-cooled PEMFC is also vital; different flow fields have an influence on the PEMFC inner temperature distribution, the PEM water content, and the PEMFC current density; Figure 9 is three different flow fields, which show the temperature and water content of PEM along channel when single fuel cell voltage is $0.6 \mathrm{~V}$.

Figure 9(a) shows that the serpentine flow field, whose temperature is the highest in the central PEM of the three flow fields; therefore, it is not optimal for air-cooled stack, especially when cooling capacity is insufficient. The reasons are that heat reactant discontinuously operates in the PEMFC and that air-cooled intensity is insufficient, which cause the overheat temperature of the PEMFC, approximately $10 \mathrm{~K}$ higher than the other two flow fields. The inner temperature of the parallel and the interdigital fields is closer to higher outlet temperature.

Figure 9(b) shows that the water content of PEM in the parallel flow field is higher, probably because of the better stack dissipating effect, and the reactant gas can also take away some heat; moreover, it is difficult for the other two flow fields to dissipate heat, which leads to the high temperature of cell.

The current densities of $\mathrm{PEMFC}$ are, respectively, $0.51983 \mathrm{~A} / \mathrm{cm}^{2}$ in the parallel, $0.5336 \mathrm{~A} / \mathrm{cm}^{2}$ in the serpentine, and $0.516 \mathrm{~A} / \mathrm{cm}^{2}$ in the interdigital fields. The current density of the three flow fields changes little under the same conditions, the serpentine field is better, mainly because of its higher temperature.

There are certain differences between air-cooled and water-cooled PEMFC, whose heat dissipating intensity varies. Thus, if the air-cooled PEMFC emphasizes uniform reaction in flow field that continuously hovers in the cell, it can be an obstacle to heat dissipation, especially when the stack is lack of air-cooled plate. In this case, the parallel flow field is a better choice.

5.2. The Optimization of Heat Dissipation Structure for AirCooled Stack. Figure 10 shows that the inlet wind speed is $0.5 \mathrm{~m} / \mathrm{s}$; when $X$ is $25 \mathrm{~mm}$, the temperature distribution in stack outlet terminal, whose temperature of both terminals is about $6 \mathrm{~K}$ higher than that of the central temperature at the height of direction $Z$, which indicates that the heat dissipation of both terminals is not perfect; therefore, it needs to enhance heat dissipation in the high temperature area under the same heat dissipation conditions; this is the reason to add irregular cooling fins. 


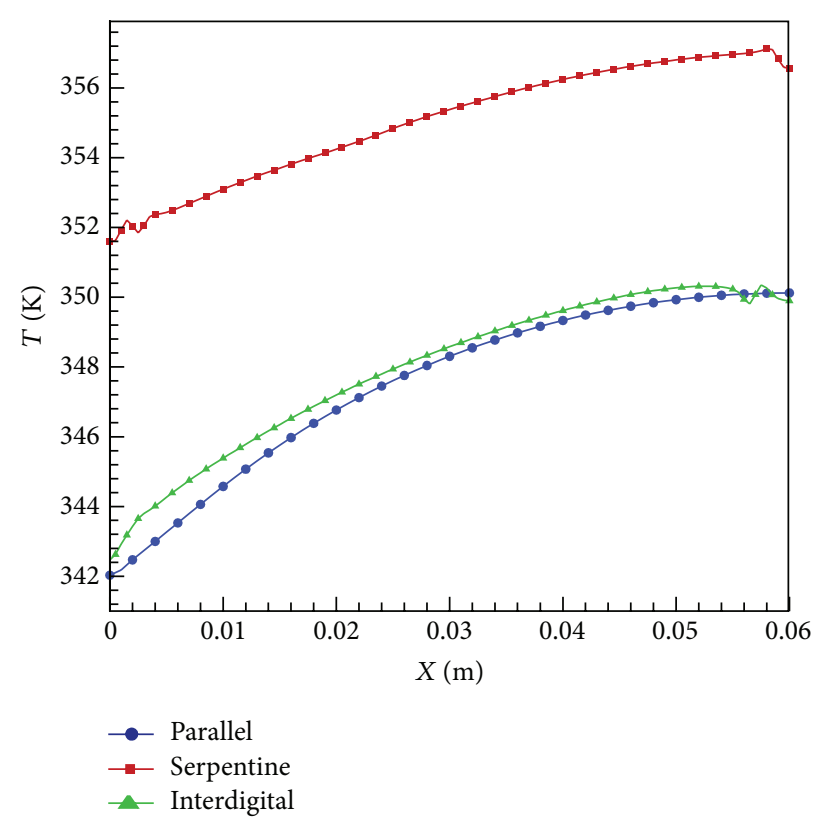

(a) Temperature curve

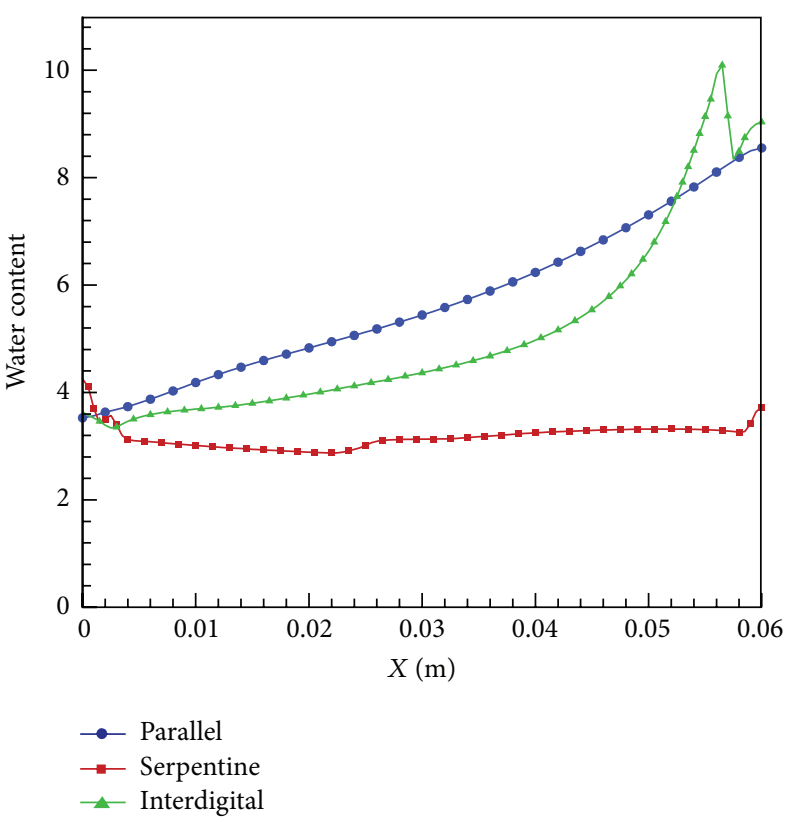

(b) Water content curve

FIGURE 9: $Y=1.23 \mathrm{~mm}$, the curves of the temperature and water content of membrane along channel.

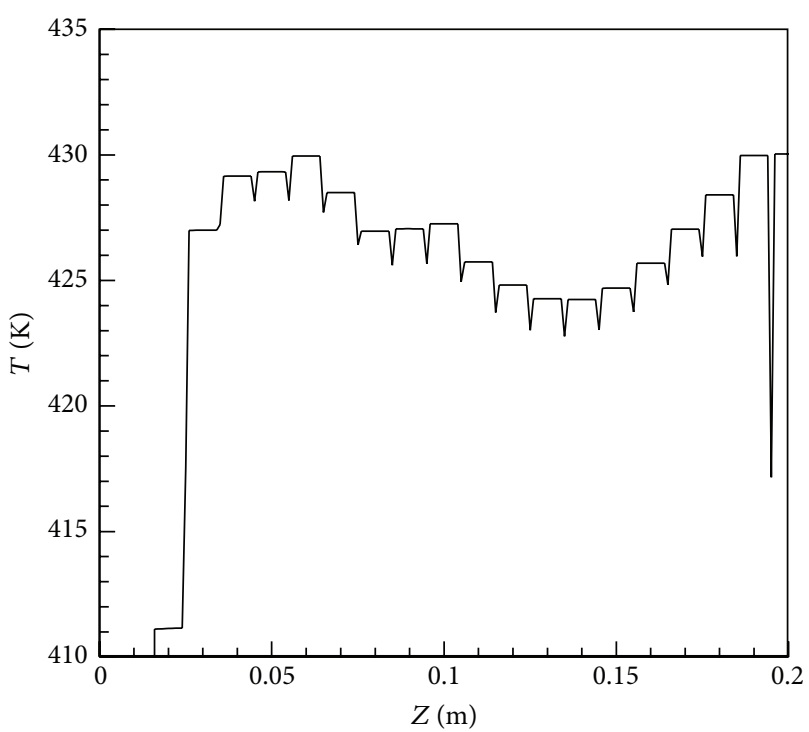

Figure 10: $V=0.5 \mathrm{~m} / \mathrm{s}, X=25 \mathrm{~mm}$, the temperature distribution in NCAF stack's outlet terminal.

Moreover, Figure 10 also manifests that the cooled wind speed is too low, which causes the high temperature of the stack, reaching a maximum of $429 \mathrm{~K}$ that the air-cooled stack cannot endure; in this case, it is necessary to increase the inlet wind speed.

Figure 11 demonstrates the temperature situation of the stack outlet under different wind speed. When the cooled wind speed is $1 \mathrm{~m} / \mathrm{s}$, temperature at the stack terminals of NCAF and CAF both reach above $360 \mathrm{~K}$, whose operating temperature exceeds $359.15 \mathrm{~K}$, which is $20 \mathrm{~K}$ higher than that of the air-cooled stack, bringing great damage to the stack. Therefore, it needs to reinforce air-cooling.

When wind speed reaches $2 \mathrm{~m} / \mathrm{s}$, the average temperature of NCAF stack outlet terminal reaches above $336 \mathrm{~K}$; however, the average temperature of the stack CAF outlet terminal is around $331 \mathrm{~K}$; therefore, CAF stack is going to satisfy the stack operating conditions. When wind speed reaches $3 \mathrm{~m} / \mathrm{s}$, the outlet terminal temperature of NCAF stack still exceeds the operating temperature of the stack; yet, the average temperature of CAF stack outlet terminal is about $326 \mathrm{~K}$ that satisfies the operating requirements of the stack; therefore, NCAF stack still needs to improve cooled wind speed. In this case, NCAF stack increases energy consumption of the fan and reduces the whole stack efficiency.

In addition, the air-cooled stack requires uniform temperature distribution; otherwise, heat dissipation unevenness will result in the extremely high temperature of some parts in the stack which damages its PEM. It makes the resistance of the stack increases a lot and its efficiency decreases, which is one of the problems of the air-cooled stack.

The wind speed is $2 \mathrm{~m} / \mathrm{s}$, which is demonstrated in Figure 12; when $Y$ is $110 \mathrm{~mm}$, the stack temperature is cloud distribution that shows that there are more focuses on the high temperature zone of stack NCAF on the both ends in height direction, whereas the high temperature zone of stack CAF focuses on the symmetry center, which is because stack CAF has the bigger heat dissipating areas in both ends, which has a better heat dissipating effect that is close to the stack operating temperature, $333.15 \mathrm{~K}$. The temperature difference of the cell in both of the stacks is ranging from 3 to $4 \mathrm{~K}$ because the simulation is undertaken under a better heat 


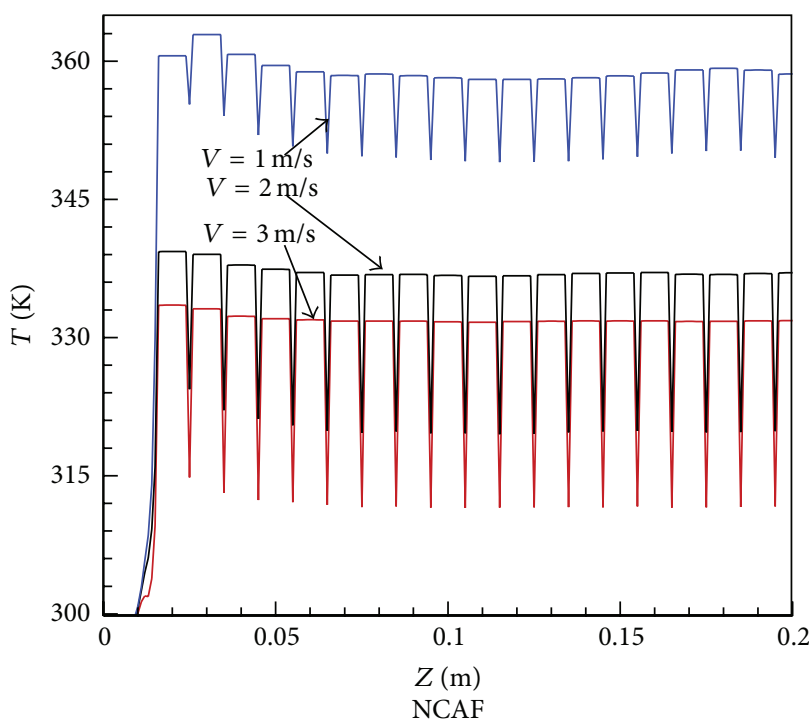

(a)

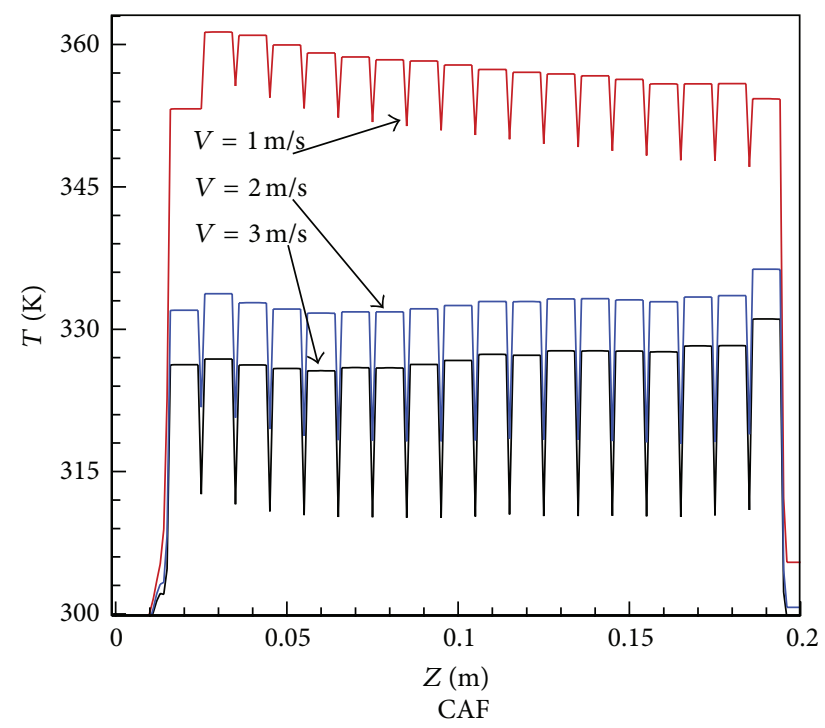

(b)

FIGURE 11: $X=25 \mathrm{~mm}$, different air-cooling speed, the temperature distribution in stack's outlet terminal.
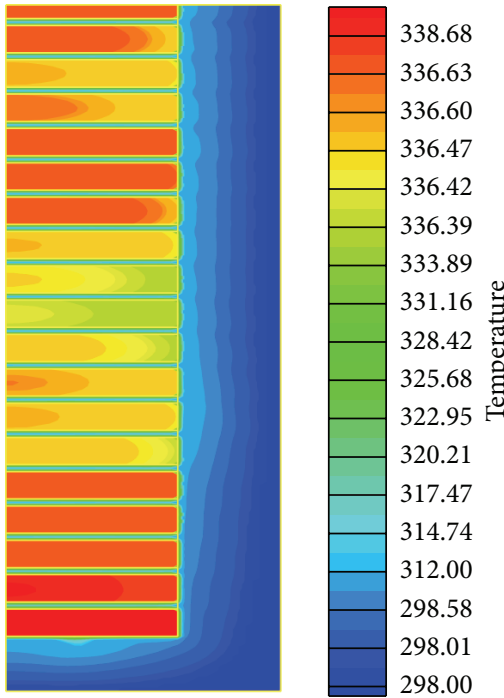

NCAF

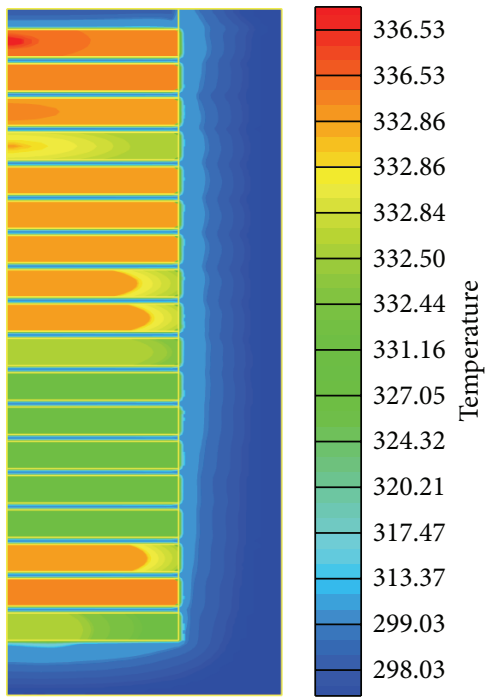

CAF

Figure $12: V=2 \mathrm{~m} / \mathrm{s}, Y=110 \mathrm{~mm}$, the temperature distribution of stack.

dissipating condition, whose stack is able to better dissipate heat. Therefore, the temperature difference of a single cell is small.

By simulation, there is a great relationship among stack performance, flow field, temperature, and humidity. As for the air-cooled stack with air in the cathode, whose anode is pure hydrogen and cathode with a $\mathrm{RH}$ of $80 \%$, the parallel flow field can improve its performance.

Under the same operating conditions, according to the temperature distribution, the irregular cooling fins are added at the stack terminals. It will be beneficial to the uniform distribution of temperature in single cell and prolong the lifespan of the stack.
5.3. Stack Temperature Analysis in Test. According to some references, the operating temperature of the PEMFC stack can reach a height exceeding approximately $390 \mathrm{~K}[19,20]$, which can enhance the stack efficiency, yet considering the security of the stack, whose operating temperature is decreased during the process of designing and manufacturing that is illustrated in Section 4.

The performance parameters of the stack change with time under the rating load testing, as is shown in Figures 13 and 14. After starting for 64 seconds, the stack begins to work normally, whose inlet temperature is around $304.15 \mathrm{~K}$, 42 seconds later, it starts to add rating load to the stack, whose voltage reaches around $66 \mathrm{~V}$, after about 20 seconds, the 


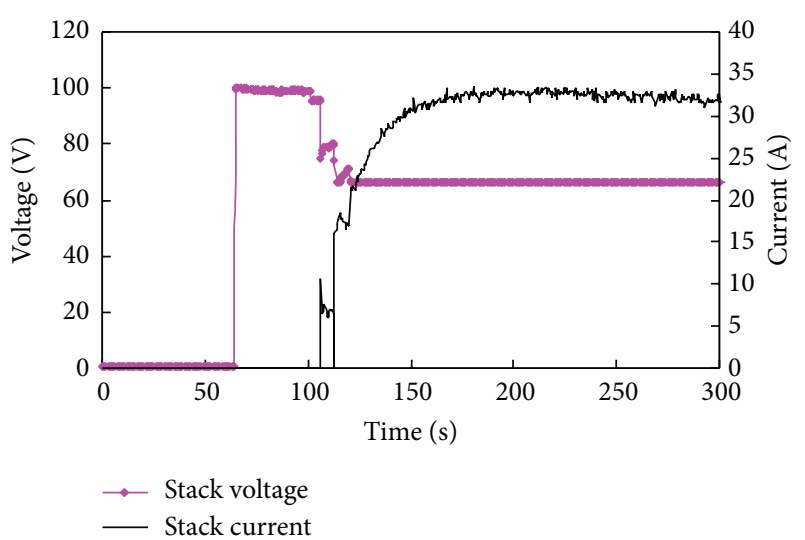

FIGURE 13: The stack current and voltage in the testing of constant load.

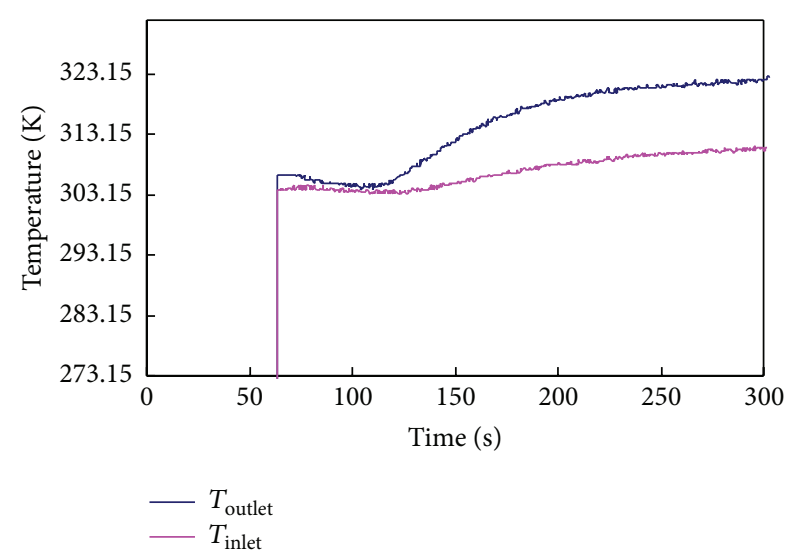

FIGURE 14: The inlet and outlet temperature of stack in the testing of constant load.

current lagged for several seconds and reaches approximately $32 \mathrm{~A}$, and afterwards, the stack voltage maintains steady; the current tends to be flat as the temperature increases. After running for 300 seconds, the outlet temperature of the stack reaches $321.15 \mathrm{~K}$, but the inlet one is $309.85 \mathrm{~K}$, which indicates that the stack temperature is $333.15 \mathrm{~K}$ lower than the required operating temperature that can dissipate heat better, reflecting the steady operating of the stack under rating power.

Figure 15 reflects changes curves for the inlet temperature of the stack under step load. The stack temperature does not change abruptly because switching the load cannot immediately change the temperature, yet, with the load increases, the stack heat increases as well, whose maximum stack temperature reaches $323.15 \mathrm{~K}$, which is controlled within the stack operating range.

Based on the testing analysis, the operating temperature of the stack is indeed insufficient and easy to produce water flooding, leading to the decrease of the efficiency; therefore, there exists a space to improve the manufacturing of the aircooled stack with higher efficiency.

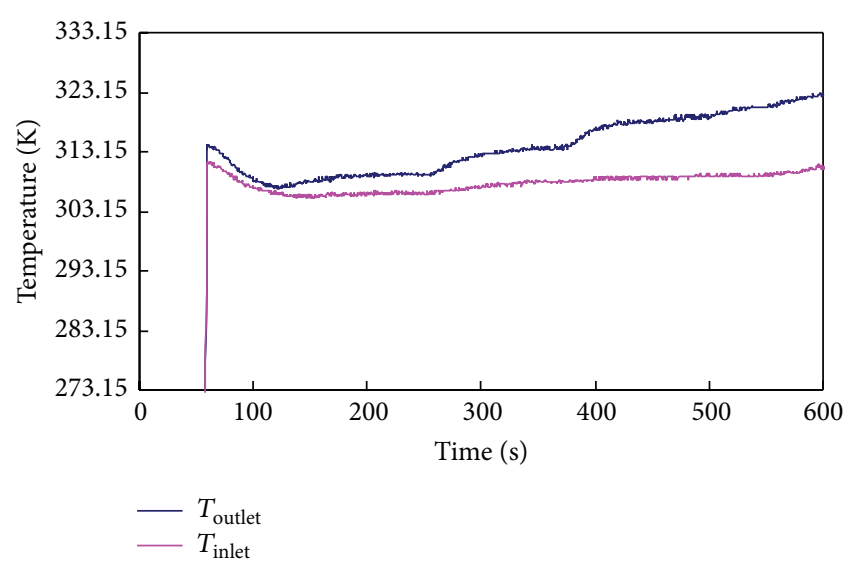

FIGURE 15: The inlet and outlet temperature of stack in the testing of step load.

\section{Conclusions}

Conclusions according to simulation and test are as follows.

(1) Simulation indicates that the CHT model is suitable for the study of air-cooled stack because surface temperature of the fuel cell continuously increases from the inlet of $333 \mathrm{~K}$ to the outlet of $349 \mathrm{~K}$, and the temperature distribution of the stack is similar to that of air-cooled fuel cell.

(2) The structure of the parallel flow field is simple, which is suitable for air-cooled stack. Because, under the voltage of $0.6 \mathrm{~V}$, the simulation shows that the temperature of serpentine flow field is $10 \mathrm{~K}$ higher than the other two kinds of flow fields; yet the water content $\mathrm{Cw}$ is the minimum; at this time, the temperature is high and the membrane is dry; interdigital flow field has a mutation in the outlet terminal, which shows that the poor draining of the outlet terminals whose $\mathrm{Cw}$ is the maximum 10, which is 3 times of that of the outlet.

(3) Optimization of the heat dissipating structure in the outlet terminals of stack can make the distribution of the stack temperature uniform, reducing the fan energy consumption. The central temperature of the NCAF stack is $6 \mathrm{~K}$ lower than that of the edge by cooling it with a wind speed of $0.5 \mathrm{~m} / \mathrm{s}$, indicating that the heat dissipation of the stack is not uniform. Under the same conditions of radiating capacity, whose wind speed of $2 \mathrm{~m} / \mathrm{s}$ can satisfy the cooling requirements of CAF stack, yet, NCAF stack requires a wind speed of $3 \mathrm{~m} / \mathrm{s}$.

(4) The air-cooled stack tends to produce water flooding under low operating temperature that results in the stack power decrease; in this case, the operating temperature requires improving in the near future so as to perfect the manufacturing of the air-cooled stack.

\section{Conflict of Interests}

The authors declare that there is no conflict of interests regarding the publication of this paper. 


\section{References}

[1] B. Boyd and K. Hooman, "Air-cooled micro-porous heat exchangers for thermal management of fuel cells," International Communications in Heat and Mass Transfer, vol. 39, no. 3, pp. 363-367, 2012.

[2] W. A. N. Wan Mohamed, R. Atan, and A. A. Ismail, "Heat transfer simulation of a single channel air-cooled polymer electrolyte membrane fuel cell stack with extended cooling surface," in Proceedings of the International Conference on Science and Social Research (CSSR '10), pp. 91-96, December 2010.

[3] M. Akbari, A. Tamayol, and M. Bahrami, "Thermal assessment of convective heat transfer in air-cooled PEMFC stacks: an experimental study," Energy Procedia, vol. 29, pp. 1-11, 2012.

[4] K. P. Adzakpa, J. Ramousse, Y. Dubé et al., "Transient air cooling thermal modeling of a PEM fuel cell," Journal of Power Sources, vol. 179, no. 1, pp. 164-176, 2008.

[5] S. Hankey and J. D. Marshall, "Impacts of urban form on future US passenger-vehicle greenhouse gas emissions," Energy Policy, vol. 38, no. 9, pp. 4880-4887, 2010.

[6] E. H. Reddy and S. Jayanti, “Thermal management strategies for a $1 \mathrm{kWe}$ stack of a high temperature proton exchange membrane fuel cell," Applied Thermal Engineering, vol. 48, pp. 465-475, 2012.

[7] J.-W. Ahn and S.-Y. Choe, "Coolant controls of a PEM fuel cell system," Journal of Power Sources, vol. 179, no. 1, pp. 252-264, 2008.

[8] http://www.arc.vt.edu/ansys_help/flu_ug/flu_ug_sec_bc_wall.html \#flu_ug_sec_wall_calc_tbc.

[9] J. C. Kurnia, A. P. Sasmito, and A. S. Mujumdar, "Numerical investigation of laminar heat transfer performance of various cooling channel designs," Applied Thermal Engineering, vol. 31, no. 6-7, pp. 1293-1304, 2011.

[10] A. P. Sasmito, J. C. Kurnia, and A. S. Mujumdar, "Numerical evaluation of various gas and coolant channel designs for high performance liquid-cooled proton exchange membrane fuel cell stacks," Energy, vol. 44, no. 1, pp. 278-291, 2012.

[11] G. Inoue, T. Yoshimoto, Y. Matsukuma, M. Minemoto, H. Itoh, and S. Tsurumaki, "Numerical analysis of relative humidity distribution in polymer electrolyte fuel cell stack including cooling water," Journal of Power Sources, vol. 162, no. 1, pp. 81-93, 2006.

[12] D. H. Jeon, S. Greenway, S. Shimpalee, and J. W. van Zee, "The effect of serpentine flow-field designs on PEM fuel cell performance," International Journal of Hydrogen Energy, vol. 33, no. 3, pp. 1052-1066, 2008.

[13] H.-I. Kim, J. H. Nam, D. Shin, T.-Y. Chung, and Y.-G. Kim, "A numerical study on liquid water exhaust capabilities of flow channels in polymer electrolyte membrane fuel cells," Current Applied Physics, vol. 10, no. 2, pp. S91-S96, 2010.

[14] K. N. Kim, D. H. Jeon, J. H. Nam, and B. M. Kim, "Numerical study of straight-parallel PEM fuel cells at automotive operation," International Journal of Hydrogen Energy, vol. 37, no. 11, pp. 9212-9227, 2012.

[15] L. Chen, H.-B. Luan, Y.-L. He, and W.-Q. Tao, "Pore-scale flow and mass transport in gas diffusion layer of proton exchange membrane fuel cell with interdigitated flow fields," International Journal of Thermal Sciences, vol. 51, no. 1, pp. 132-144, 2012.

[16] M. A. R. S. Al-Baghdadi and H. A. K. S. Al-Janabi, "Effect of operating parameters on the hygro-thermal stresses in proton exchange membranes of fuel cells," International Journal of Hydrogen Energy, vol. 32, no. 17, pp. 4510-4522, 2007.
[17] J. E. Dawes, N. S. Hanspal, O. A. Family, and A. Turan, “Threedimensional CFD modelling of PEM fuel cells: an investigation into the effects of water flooding," Chemical Engineering Science, vol. 64, no. 12, pp. 2781-2794, 2009.

[18] C.-Y. Jung, C.-S. Lee, and S.-C. Yi, “Computational analysis of transport phenomena in proton exchange membrane for polymer electrolyte fuel cells," Journal of Membrane Science, vol. 309, no. 1-2, pp. 1-6, 2008.

[19] J. Peng and S. J. Lee, "Numerical simulation of proton exchange membrane fuel cells at high operating temperature," Journal of Power Sources, vol. 162, no. 2, pp. 1182-1191, 2006.

[20] P. Pfeifer, C. Wall, O. Jensen, H. Hahn, and M. Fichtner, "Thermal coupling of a high temperature PEM fuel cell with a complex hydride tank," International Journal of Hydrogen Energy, vol. 34, no. 8, pp. 3457-3466, 2009. 


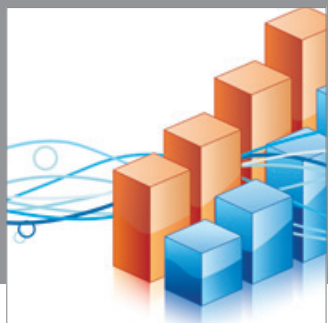

Advances in

Operations Research

mansans

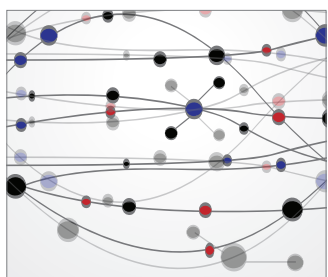

The Scientific World Journal
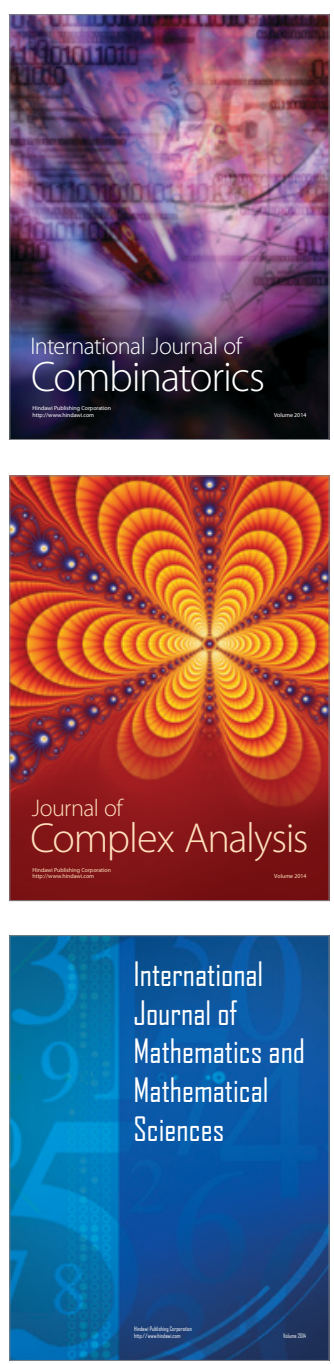
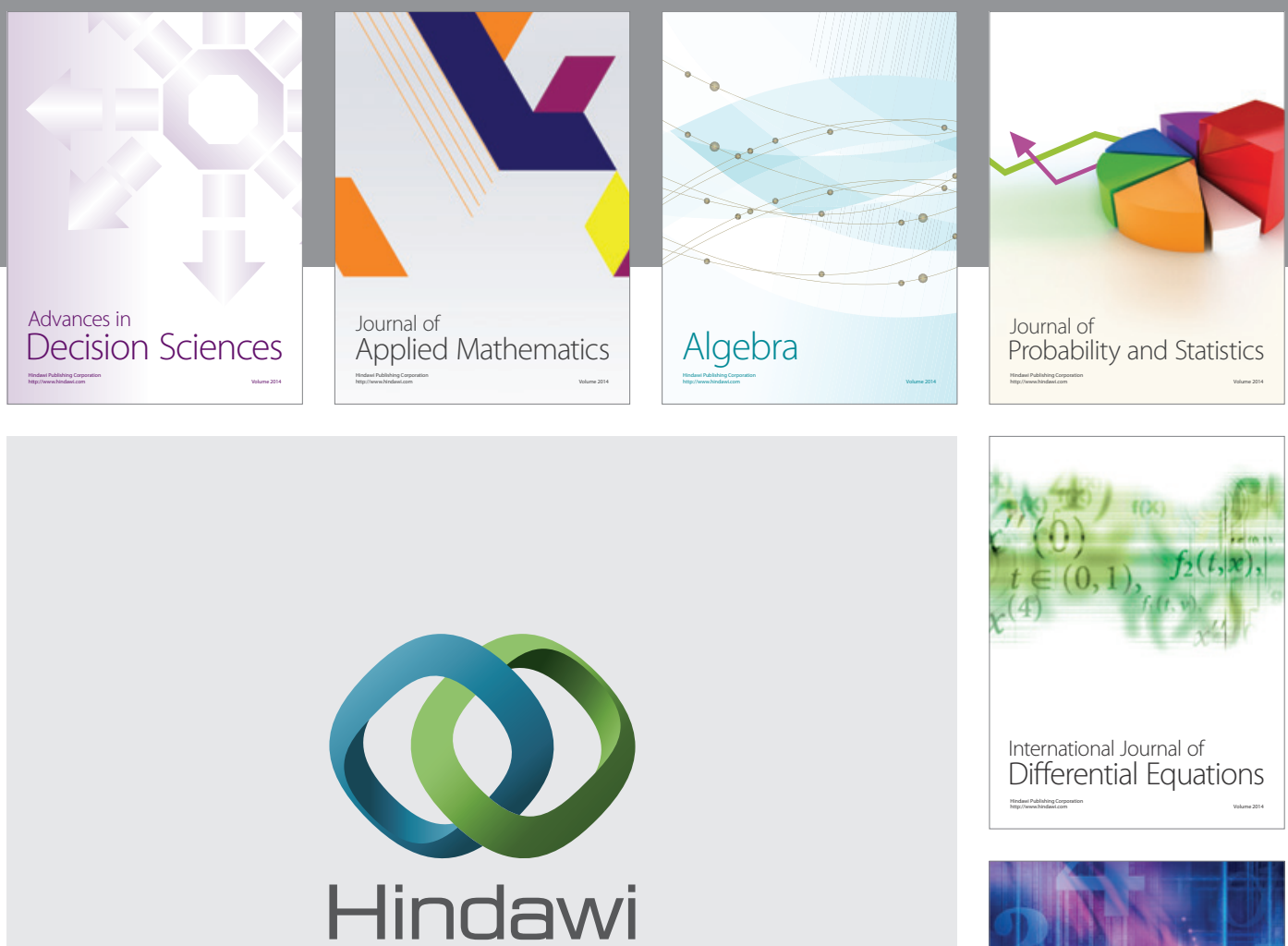

Submit your manuscripts at http://www.hindawi.com
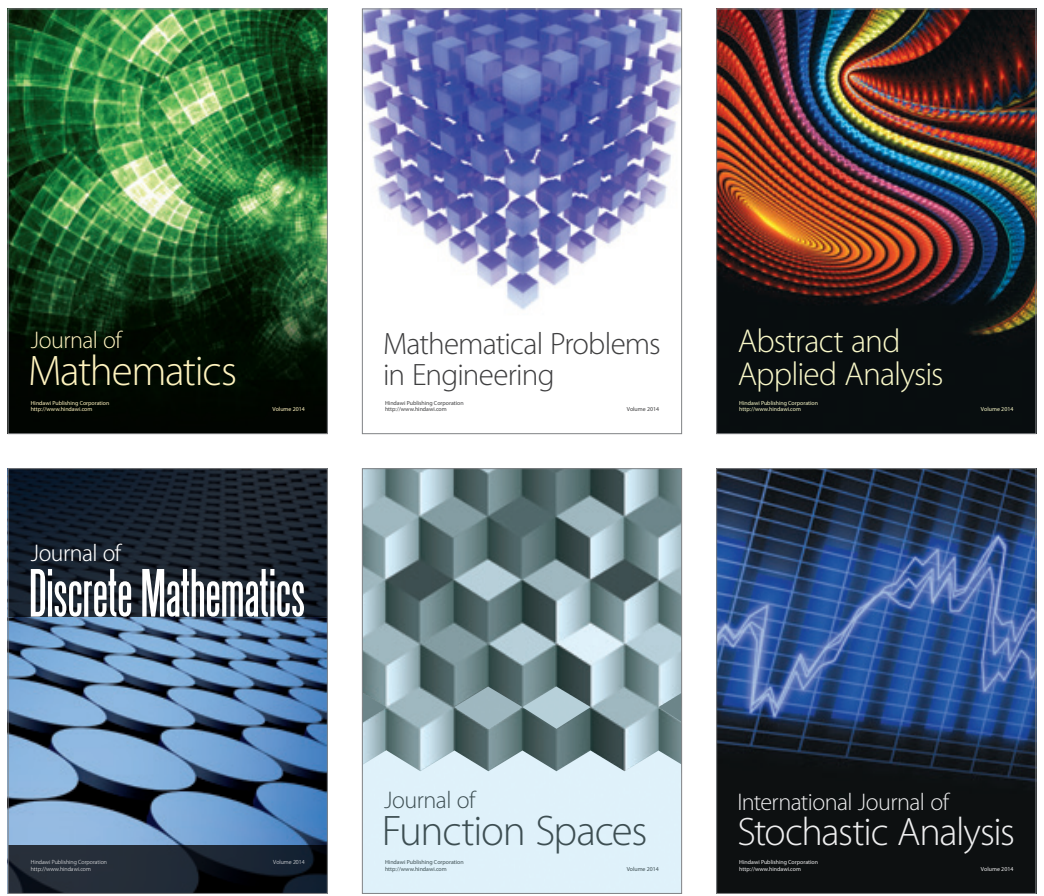

Journal of

Function Spaces

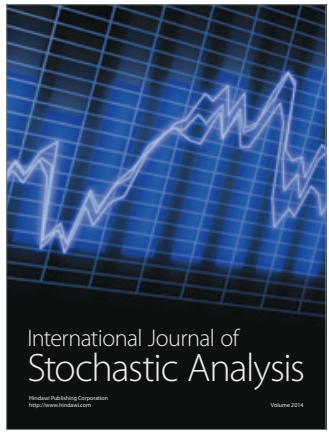

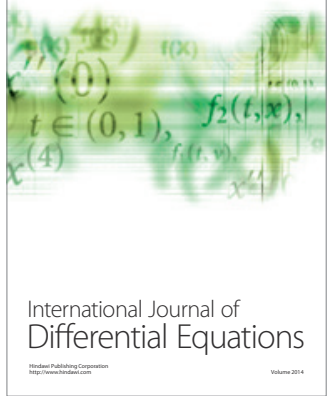
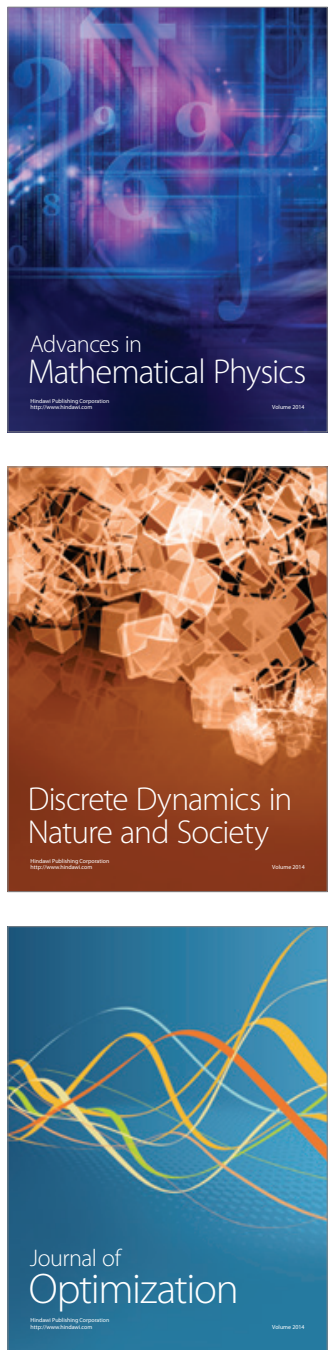